\title{
Do differences in plasticity during early growth lead to differing success in competition? A test using four co-occurring annual Papaver
}

\author{
Per Milberg, Jan Karlsson, Lotta Wessman and Laila Karlsson
}

\section{Linköping University Post Print}

\section{Tweet}

N.B.: When citing this work, cite the original article.

This is the pre-reviewed version of the following article:

Per Milberg, Jan Karlsson, Lotta Wessman and Laila Karlsson, Do differences in plasticity during early growth lead to differing success in competition? A test using four co-occurring annual Papaver, 2014, Plant Species Biology, (29), 1, 92-100.

which has been published in final form at:

http://dx.doi.org/10.1111/j.1442-1984.2012.00394.x

Copyright: Wiley-Blackwell: No OnlineOpen http://eu.wiley.com/WileyCDA/Brand/id-35.html

Postprint available at: Linköping University Electronic Press http://urn.kb.se/resolve?urn=urn:nbn:se:liu:diva-103286 
1 MS intended for Plant Species Biology

2

3 Do differences in plasticity during early growth lead to differing success in competition?

4 A test using four co-occurring annual Papaver

5

6 PER MILBERG ${ }^{\mathrm{a}, \mathrm{b}}$, JAN KARLSSON $^{\mathrm{a}}$, LOTTA WESSMAN ${ }^{\mathrm{a}}$ and LAILA M. KARLSSON ${ }^{\mathrm{a}, \mathrm{b}}$

$7 \quad{ }^{a}$ IFM Biology, Division of Ecology, Linköping University, SE-581 83 Linköping, Sweden

$8 \quad{ }^{\mathrm{b}}$ Department of Crop Production Ecology, SLU, Box 7043, 75007 Uppsala, Sweden

9

10 Running head: Plasticity and competitive response

11

12 The authors have no commercial interest in the findings presented.

13

14 Correspondence: Laila Karlsson

15 Email:email@lailakarlsson.se

16

174 Figures

$18 \quad 2$ Tables

194852 words 
Do differences in plasticity during early growth lead to differing success in competition? A test using four co-occurring annual Papaver

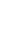

PER MILBERG ${ }^{\mathrm{a}, \mathrm{b}}, \mathrm{JAN}^{\mathrm{K} A R L S S O N}{ }^{\mathrm{a}}$, LOTTA WESSMAN $^{\mathrm{a}}$ and LAILA M. KARLSSON ${ }^{\mathrm{a}, \mathrm{b}}$

${ }^{a}$ IFM Biology, Division of Ecology, Linköping University, SE-581 83 Linköping, Sweden

${ }^{\mathrm{b}}$ Department of Crop Production Ecology, SLU, Box 7043, 75007 Uppsala, Sweden

\section{Correspondence: Laila Karlsson}

Email: email@lailakarlsson.se

\section{Abstract}

Plant species differ in their ability to transform available recourses to biomass and to respond in a plastic way to environmental circumstances; we hypothesized that such differences among four weed taxa of Papaver would explain differences in their competitive response.

We first compared two populations each of Papaver rhoeas L., P. dubium L. ssp. dubium, P. dubium L. ssp. lecoqii (Lamotte) Syme and P. argemone L., grown in greenhouse for six weeks in a nutrient gradient combined with two light treatments to elucidate possible differences in responses. As there were clear differences, a second experiment evaluated whether these differences also meant differences in competitive response, during early growth, when tested against two crops (wheat, rape). The assumption that competitive response was linked to the ability to transform nutrient and light to biomass was not supported: even though differences in extent of plasticity existed, the effect of competition was similar for the taxa. Thus, higher plasticity and ability to transform available recourses to biomass did not lead to stronger competitiveness for Papaver during early growth.

Keywords: crop, nutrient, phenotypic plasticity, poppy. 
Introduction

Closely related species as well as those with similar ecological affinity can differ substantially

in the amount of biomass they produce when tested over a range of controlled environments (e.g. Milberg et al. 1999, Gianoli \& Gonzales-Teuber 2005, Griffith \& Sultan 2005, Muth \& Pigliucci 2006, Barisic et al. 2006). Despite the potentially large importance for explaining success in competition in general (Daehler 2003, Cahill et al. 2005, Miner et al. 2005, Peacor et al. 2006, Richards et al. 2006), or in an arable land scenario (Håkansson 2003), there seems to be a paucity of direct experiments testing the assumption that a more plastic species is likely to compete better over a wide range of conditions than the less plastic one (Peacor et al. 2006, Richards et al. 2006). One exception is the study by Poorter and Lambers (1986) who showed that a more plastic genotype of Plantago major competed better than a less plastic one. Regarding invasive species, an invasive population of Ceratophyllum demersum was found to be more plastic than a non-invasive one (Hyldegaard \& Brix 2012), five invasive species were generally more plastic than five native species on Hawaii (Funk 2008), but there was no general difference in extent of plasticity between exotic invasive species and native species when 40 species in Spain were pairwise compared (Godoy et al. 2011). However, a meta-analysis showed invasive species being generally more plastic than none-invasive species (Davidson et al. 2011). In the present study, we focus on two aspects relevant for an arable field scenario: (1) What is the extent of variation regarding plasticity in ability to transform resources into biomass among closely related annual weeds? (2) Do such (possible) differences between species have any bearing on explaining differences in competitive response (competitive tolerance)? We addressed these questions in two greenhouse experiments involving four closely related taxa within the genus Papaver (Papaveraceae). The four taxa co-occur on 
arable land in Sweden, but differ in their seriousness as weeds, making them a suitable group for investigation of possible underlying reasons for differences in performance in competition with other species. The first experiment aimed at describing the biomass produced under a range of environments as a way to evaluate the taxa's extent of plasticity in ability to transform resources into biomass, while the second experiment evaluated and compared their competitive response when grown with any of two crop species, as well as their competitive effect on the crops.

\section{Materials and methods}

\section{Plant material}

The selected taxa (Table 1) were four closely related Papaver, being rosette-forming facultative winter annuals. The seeds have a relatively strong dormancy, and the general dormancy and germination pattern explains how germination can occur mainly in autumns and springs in warmer and colder environments, respectively (Karlsson and Milberg 2007). The taxa have similar seed mass (Table 1) but differ in final height, with the flower stalk being longest for P.rhoeas and shortest for P. argemone (Jonsell et al. 2001). All occur on arable land in Europe, north to ca $60^{\circ}$ in Sweden. The taxa differ in distribution by P. dubium spp lecoqii being restricted to the east of Sweden (Jonsell et al. 2001) and, in contrast to P.rhoeas and the two P. dubium, P. argemone is not present in southernmost Europe or in Northern Africa (Hultén and Fries 1986, Kadereit 1988). Papaver rhoeas occurs in addition as a weed worldwide (Holm et al. 1997). In Scandinavia, all four taxa co-occur in various constellations and we have observed all four in the same field (personal observation). Papaver rhoeas is a close relative of the two $P$. dubium subspecies, while $P$. argemone is more distantly related (Carolan et al. 2006). As annual weeds in general, the four taxa exhibit substantial phenotypic plasticity (McNaughton and Harper 1964). 
For each taxa, we used two seed batches (replicates) originating from each of two wild weed populations southern Sweden (Table 1). For each batch, seeds had been collected from ca. 30 plants. The seeds in a batch were thoroughly mixed, dried indoors about ten days at ca $20^{\circ} \mathrm{C}$ and then stored in a freezer $\left(-12^{\circ} \mathrm{C}\right)$ until used.

\section{Common greenhouse procedures}

Experiments were conducted in a greenhouse, where seedlings were grown under a range of conditions in narrow plastic pots placed in special trays designed to hold 98 pots (Ray Leach “Cone-tainer" Single Cell System, USA). Pots had a volume of $164 \mathrm{~mL}$, a height of $210 \mathrm{~mm}$ and drainage holes in the bottom. Washed quarts sand (Baskarpsand 35, AB Baskarpsand, Habo, Sweden) was used as growth medium. The sand had been screened through 0.125 and $0.71 \mathrm{~mm}$ mesh and after screening $80 \%$ of the sand had a grain-size between 0.18 and 0.50 mm. The content of silica was $91.3 \%$.

The greenhouse was temperature-regulated, with target temperatures set to $20^{\circ} \mathrm{C}$ in daytime and $10^{\circ} \mathrm{C}$ in night $(12 \mathrm{~h} / 12 \mathrm{~h})$. The temperature was monitored during the experiments (Tinytag, Gemini Data Loggers). Incoming daylight was supplemented by lamps (Osram Vialox $400 \mathrm{~W}$ Nav-T Super (Son-T Plus)). The trays were placed on a table; which in turn was placed centrally in the greenhouse. The plants were watered with tepid tap-water every to every third day, depending on their size and weather.

Nutrient gradients were created by adding different amounts of small granules of a slow-release fertilizer (Osmocote: Start 2-3 month. Grace-Sierra, International, Heerlen, the Netherlands) that had been sieved to reduce their variation in size, resulting in ca. $2 \mathrm{~mm}$ diameter. This fertilizer consists of $16 \% \mathrm{~N}, 3.5 \% \mathrm{P}, 9.1 \% \mathrm{~K}, 1.2 \% \mathrm{Mg}$ and trace elements. 
121 Seeds were sown, in January 2003, on two sheets of filter paper (90 mm, Munktell 1003) in

122 Petri dishes. The filter papers were moistened with gibberellic acid (1000 $\mathrm{mg} \mathrm{L}^{-1}$ of $\mathrm{GA}_{3}$,

123 Sigma Chemical Co., USA) to enforce germination. The Petri dishes were sealed with

124 parafilm and incubated in light/darkness $(12 \mathrm{~h} / 12 \mathrm{~h})$ and in different temperature regimes, $P$.

125 dubium ssp. lecoqii in $25 / 15^{\circ} \mathrm{C}, P$. dubium ssp. dubium in $20 / 10^{\circ} \mathrm{C}, P$. argemone and $P$.

126 rhoeas in a constant temperature of $5^{\circ} \mathrm{C}$. These temperatures regimes were selected based on

127 germination experiments on these seed batches (Karlsson \& Milberg 2003, 2007). Two of the

128 collections (P. dubium ssp. dubium from Tallbacken and P. dubium ssp. lecoqii from

129 Vadstena) were particularly difficult to germinate and therefore, some Petri dishes were also

130 placed at other temperature regimes $\left(5,15 / 5,20 / 10,25 / 15^{\circ} \mathrm{C}\right)$. When a seed had germinated to

131 the extent that the radicle was visible, about $1 \mathrm{~mm}$, the germinant was transplanted to the

132 plastic pots in the greenhouse. Initially, there were three seedlings per pot and the trays were

133 covered with transparent plastic for 2-6 days to enhance seedling establishment. Two to three

134 weeks after planting, the pots were thinned so that only one plant remained in each pot.

135 Before transplant, the pots had been filled with sand to about $25 \mathrm{~mm}$ from the rim.

136 Then, the nutrient granules were added and finally, the pots were topped up with $15 \mathrm{~mm}$ of

137 additional sand. There were 9 nutrient treatments $(0,1,2,4,8,16,32,64,128$ granules)

138 combined with two light treatments (full light and shaded) in a full factorial design with seven

139 replicates. In total, there were 16 trays with 63 pots in each. To make the environment as

140 similar as possible for all plants, the trays were rearranged on the table every second day.

141 The light at noon in the full light treatment was measured with a photometer at nine

142 measuring points at germinant level. On a cloudy day, $218 \mu \mathrm{mol} \mathrm{m} \mathrm{m}^{-2} \mathrm{~s}^{-1}$ was recorded and on a

143 sun hazy day $282 \mu \mathrm{mol} \mathrm{m} \mathrm{m}^{-2}$. In the shading treatment, the trays were placed in boxes, one

144 tray per box, made from particle board and with four layers of grey plastic mosquito net

145 (mask width $1 \mathrm{~mm}$, Poly-Produkter, Göteborg, Sweden) on the top. There was a $200 \mathrm{~mm}$ 
146 distance between the surface of the pots and the net. This shading treatment reduced light to

$14720 \%$ of that of the full light (as recorded at noon), a reduction typical of a relatively dense

148 crop stand in Sweden (Andersson \& Milberg 1996), and which gives a difference in light

149 intensity that affected 46 grassland species studied by Semchenko et al. (2012). Average daily

150 maximum temperature during the experiment was $25.8^{\circ} \mathrm{C}(\mathrm{SD} 4.7)$ while average daily

151 minimum temperature was $9.5^{\circ} \mathrm{C}(\mathrm{SD} 0.7)$.

152 The harvest started on the 25th of March and continued to the 16th of April. By harvest, 153 each plant had spent 44 days in the greenhouse. The plants were gently removed from their 154 pots and the roots were carefully washed in water. The maximum length of roots (defined as

155 root plus hypocotyl) was measured stretched out on a sheet of millimetre graded paper, as was

156 shoot length (i.e. epicotyl) in case of etiolation (only recordable in the shaded treatment).

157 Biomass of shoots and roots were noted after being dried in $75^{\circ} \mathrm{C}$ for a minimum of $24 \mathrm{~h}$.

159 Second experiment: intra-clade differentiation in competitive response

160 In January 2004, Papaver seeds were exposed to gibberellic acid as above. This time, the

161 Petri dishes with filter paper were placed in a greenhouse at approximately $25 / 15$, except for

$162 \quad P$. argemone that was placed at $20 / 10$. One seed population of $P$. dubium spp. dubium

163 germinated poorly, so some seeds were also subjected to a higher gibberellic acid solution

$164\left(2000 \mathrm{mg} \mathrm{L}^{-1}\right)$.

165 Autumn-sown cultivars of two crop species were used as competitor: winter wheat

166 Triticum aestivum L. 'Olivin' and winter rape Brassica napus L. 'Silvia'. Seeds were

167 germinated in Petri dishes (without $\mathrm{GA}_{3}$ ) in the greenhouse. As the rape seeds had been

168 chemically treated against insects, the testa was removed before the germinant was

169 transplanted to pots, as a precaution. 
Combinations of two germinants, one crop and one Papaver, was simultaneously

171 planted in the narrow pots containing different amounts of nutrients. In this experiment, the nutrient gradient consisted of $0,1,4,16$ and 64 granules. There were five replicates per treatment. In addition, there was a series of control plots containing single specimens of the eight Papaver populations as well as single specimens of the two crops. In total, there were 650 pots, randomly placed in trays.

Light, measured at germinant level, was 254 and $372 \mu \mathrm{mol} \mathrm{m}^{-2} \mathrm{~s}^{-1}$ on a cloudy and sunny day, respectively. Average daily maximum temperature during the experiment was $21.5^{\circ} \mathrm{C}(\mathrm{SD} 3.08)$ while average daily minimum temperature was $10.6^{\circ} \mathrm{C}(1.64)$.

The experiment was terminated after six weeks growth in the greenhouse when biomass of crop and weed was recorded. Observations and measurements in the first experiment had shown that the four taxa differed in biomass accumulation, but were otherwise morphologically very similar when grown in full light. This was not unexpected, considering how closely related they are, and a justification for focusing on biomass as the main outcome variable in the competition experiment. As the roots of the paired plants were, in many cases, very difficult to separate, only above-ground biomass was considered.

\section{Statistical analyses}

\section{$\underline{\text { First experiment }}$}

The four taxa have similar seed mass (Table 1), and are comparatively similar in seedling morphology, which simplifies comparison of the biomass produced. The minimum size of the plants grown (without nutrients and in reduced light) would be mainly determined by seed reserves, that are similar (and small) in these four taxa. The maximum plant size, however, would be mainly determined by possible intrinsic properties of growth in a particular species. Therefore, we analysed this experiment with ANOVA. 
Of the 1008 pots with plants, 955 contained living plants at harvest. The 53 losses were not evenly distributed among the treatments; most losses were found at the highest nutrient level ( $\mathrm{N}=23)$, and within two populations (Tallbacken $\mathrm{N}=19$; Omberg $\mathrm{N}=14$ ) and one species ( $P$. dubium spp. dubium $\mathrm{N}=21$ ). As we used population averages in the statistical analyses, this unbalanced occurrence of missing values had no practical consequences. We conducted two ANOVAs, with (i) average $\log _{10}$-transformed biomass, and (ii) average root-mass/shoot-mass as response variables, using the following factors: taxon, light/shade, nutrient and their interaction factors. Of interest to our aims were "taxon" and the interaction factors that involved "taxon".

In the early part of life, the species studied are very similar in morphology, and only one of the other variables recorded turned out to vary between species: the ability to etiolate in shade. As these differences were small, and on an integer scale, we used GLM (poisson distribution, log-link) to evaluate differences between species. Finally, for display purposes, we returned to the raw data $(\mathrm{N}=955)$ and fitted species-wise lowess (locally weighted scatterplot smoothing) curves (stiffness 0.5) per species along the nutrient gradient.

\section{$\underline{\text { Second experiment }}$}

Of the 400 pots, 38 were lost due to mortality of Papaver or the crop. These missing values were evenly distributed among the treatments. To be able to pair data on plants grown with and without competition, we used population average per treatment.

The effect of competition has been evaluated in numerous ways, mainly through indices (Weigelt \& Jolliffe 2003). We followed the protocol suggested by Lamb et al. (2006) which aim at finding the simplest model possible for accurate description of data. In this stepwise procedure, we first assumed that size-dependence might exist, and fitted the model (1) below to the global data: 


$$
\text { Biomass }_{\text {mix }}=\mathrm{k} 1+\mathrm{k} 2 *\left(\text { Biomass }_{\text {control }}\right)^{\mathrm{k} 3}
$$

221 where Biomass $_{\text {mix }}$ is the biomass of the target taxon when grown in mixture and Biomass control when it is grown without competition; k1, k2 and k3 are constants. Second, eliminating k1 did not improve the model (AIC increased from 299.1 to 299.8), suggesting that size-dependence

can be ignored. Third, setting k3=1 only slightly improved the explanatory power of the model (AIC decreased from 299.8 to 298.7), suggesting that a linear model would not be much inferior to a more complex one. Hence, we turned to ANOVA for analyses, using Biomass $_{\text {control }}$ as covariable and "nutrient" $(\mathrm{N}=5)$ and "weed species identity" $(\mathrm{N}=4)$ as categorical variables (following Jasieński \& Bazzaz 1999, Cahill et al. 2005), and using the two populations per species as replicates. To reduce the risk for a Type I error, we conducted one analysis per crop and one with both crops together, i.e. three ANOVAs in total. level as the only explanatory variable. Thereby, we had eliminated the effect of nutrients and could express the results, per Papaver taxa or crops, as deviations from the average. In this way we could highlight possible effects of competitors and differences between species.

\section{Results}

\section{First experiment}

Biomass: There were highly significant differences between taxa, but the interaction factors involving "taxon" were non-significant (Table 2). As expected, light conditions and nutrient availability greatly influenced biomass (Table 2). There was also a strong interaction between

241 light and nutrient (Table 2), probably reflecting a slower growth in the shade, preventing 242 plants to take full advantage of the available nutrients (Fig. 1). It seems that the nutrient 243 gradient in the experiment encompassed the optimum, as all the measured characters, with 244 one exception (above ground biomass in light treatment), plateaued or decreased for all taxa 
at the highest nutrient level (Fig. 1). On average, $P$. rhoeas produced most biomass (significantly larger than all other taxa, in a Tukey HSD), while $P$. dubium spp. dubium produced least. Of the two intermediate taxa, P. dubium ssp. lecoqii produced slightly more biomass than $P$. argemone, but not significantly so (Tukey HSD).

Root/shoot ratio: The ANOVA of root/shoot ratio (Table 2) revealed similar pattern as the one for biomass. i.e. taxa differed in their root/shoot ratios (Fig. 2).

Etiolation: No shoot elongation was recorded in light, but species differed in their elongation in shade (Wald $\left.\chi_{(3)}^{2}=237.4 ; \mathrm{P}<0.0001\right)$. Papaver argemone elongated least, Papaver dubium ssp. dubium and P. dubium ssp. lecoqii were intermediate and quite similar in their response while P. rhoeas was the taxon that elongated most (Fig. 1).

\section{Second experiment}

All Papaver were negatively affected by competition with crop (Fig. 3a), but none of the ANOVAs conducted detected an effect of weed species (i.e. taxa, Table 1) on the biomass of plants subjected to competition (both crops together $\mathrm{F}_{(3,39)}=1.386, \mathrm{P}=0.261$; rape $\mathrm{F}_{(3,19)}=$ 1.088, $\mathrm{P}=0.378$; wheat $\mathrm{F}_{(3,19)}=1.580, \mathrm{P}=0.227$; Fig. 3a).

As expected, considering the relative short-term nature of the experiment, the crops, that are large-seeded, were not much affected by the presence of a weed (Fig. 3b). A preliminary t-test (on log-transformed biomass data) indicated that the presence of a weed had a very small effects on the rape crop (average difference rape $-0.0446, \mathrm{t}=-1.91 ; \mathrm{P}=0.063$ ) and a negligible one on wheat $(+0.0420, \mathrm{t}=1.38, \mathrm{P}=0.176)$. Hence, we did not consider data on the crops grown with or without competition further.

\section{Discussion}

Ability to transform resources into biomass 
270 The four related Papaver taxa (phylogenetics revealed by Carolan et al. 2006) differed

271 substantially in size and morphology after 44 days growth in a variety of growth conditions

272 (Fig. 1). There was, however, no apparent phylogenetic pattern in growth capacity among the

273 four species: the phylogenetically most distant taxon, P. argemone (Carolan et al. 2006),

274 performed intermediately with the two sub-species of $P$. dubium, the two latter differing

275 especially regarding above-ground biomass response to the gradient of nutrients (Figs. 1, 4).

276 Papaver rhoeas, the taxon that responded strongest to the gradient (Fig. 1), belongs to the

277 same clade as P. dubium but not the same as P. argemone (Carolan et al. 2006). Hence,

278 differentiation in capacity to exploit resources seems to develop much faster than speciation

279 (Fig. 4).

280 The root/shoot ratios were low in shaded conditions for all the taxa (Fig. 2). It is

281 apparent that the plants are allocating more to growing green parts, to maximise their

282 photosynthetic capacity, than to their roots. For the plants grown in full light conditions, the

283 ratios between root and shoot were rather similar over the range of plant sizes involved (Fig. 284 2).

285 The response invoked by shade differed quantitatively among species, as judged by the 286 etiolation recorded (Fig. 1): from a maximum of 3 to $9 \mathrm{~mm}$. Even after accounting for 287 differences in plant size, etiolation of $P$. $d$. dubium was twice that of $P$. argemone, taxa that 288 produced similar amounts of biomass (Fig. 1). Hence, even related species, occurring within 289 the same habitat, may differ in extent of plasticity (Figs. 1, 2; cf. Griffith \& Sultan 2005) and 290 in general allocation of biomass (Fig. 1; Jia et al. 2010).

Plasticity as predictor of competitiveness

293 In contrast to Poorter and Lambers' (1986) study of Plantago major, we were unable to show 294 a difference in competitive response, or competitive effect, among the closely related Papaver 
species (Fig. 3a) despite the fact that they differed in their ability to transform resources into biomass; seed mass is similar (Table 1) but biomass produced without nutrient differed between taxa (Fig. 1). Could our inability to document differentiation in competitive response, as well as competitive effect, be due to the relatively short duration of our experiment, i.e. that competition had not yet manifesting itself in biomass loss? This was, as expected, the case for the crop data (competitive effect, Fig. 3b), but the Papaver species were severely hampered by competition (Fig. 3a), leaving plenty of room for manifestation of inter-taxon differences in competitive response. Thus, the theory that higher extent of plasticity gives a stronger competitor was not supported for Papaver during early growth. Analogous to competition, high extent of plasticity is also assumed to be correlated to invasiveness. This theory was supported for different populations of one aquatic species (Hyldegaard \& Brix 2012) and by Funk (2008), when five invasive species were compared with five native. However, the theory was not supported when 20 native and 20 exotic invasive species were compared (Godoy et al. 2011). Funk (2008) and Goday et al. (2011) included, respectively, one and five pairs of species belonging to the same genus. Of these, there were two pairs in which the exotic species was more plastic than the native. Thus, as for competiveness (Fig. 3), higher extent of plasticity is not necessarily an explanation to stronger invasiveness (Godoy et al. 2011), even though invasive species are generally more plastic than none-invasive species (Davidson et al. 2011).

\section{Field implications}

Transferring these results outside the greenhouse, one would expect that $P$. rhoeas is the one best fitted in a modern agricultural landscape. It had the highest biomass, even at low levels of nutrient, and it had the highest values of etiolation. Along the same arguments, Papaver argemone would be the least fitted. In fact, the former species is regarded a serious weed at 
several localities (Holm et al. 1997) and seems to be increasing, albeit presumably because of development of herbicide resistance, while the latter is rare and probably decreasing (Aronsson 1999, Nilsson \& Nilsson 2004). Performance during later stages of growth may determine the outcome for these weeds in competition with crops. Despite developing similarly during early growth when subjected to competition (Fig. 3), the four taxa differ in final height, with $P$. argemone, $P$. dubium and $P$. rhoeas reaching 66, 80 and $100 \mathrm{~cm}$, respectively (Jonsell et al. 2001). Thus, $P$. rhoeas is larger than the other during early growth without competitor (Fig. 1) and higher when mature in the field (Jonsell et al. 2001). The ability to grow large may itself be the reason for this taxa being the most serious weed of the Papaver taxa studied here, despite the fact that differences could not be recorded during early growth when competition occurred.

In conclusion, even closely related species can differ substantially regarding plasticity in biomass allocation and nutrient utilization, but such differences must not necessarily lead to differences in competitive response during early growth. However, biomass allocation and nutrient utilization will probably affect final size and other characteristics of species, which can explain differences in competitive response at maturity, which in turn may be part of the explanation to differences in worldwide distribution also of other closely related species than the Papaver studied here. It remains for future studies of groups of closely related species to reveal the general importance of plasticity on competitive response.

\section{Acknowledgements}

Formas provided partial financial support and we thank colleagues at the Department of Crop Production Ecology for various support.

\section{References}


Andersson T. N. \& Milberg P. (1996) Weed performance in crop rotations with and without leys and at different nitrogen levels. Annals of Applied Biology 128: 505-518.

Aronsson M., ed. (1999) Rödlistade kärlväxter i Sverige. Artfakta, Volum 1 \& 2. Artdatabanken, SLU, Uppsala, Sweden.

Barisic N., Stojkovic B. \& Tarasjev A. (2006) Plastic responses to light intensity and planting density in three Lamium species. Plant Systematics and Evolution 262: 25-36.

Cahill J. A., Kembel S. W. \& Gustafson D. J. (2005) Differential genetic influences on competitive effect and response in Arabidopsis thaliana. Journal of Ecology 93: 958967.

Carolan J. C., Hook I. L. I., Chase M. W., Kadereit, J. W. \& Hodkinson T. R. (2006) Phylogenetics of Papaver and related genera based on DNA sequences from ITS nuclear ribosomal DNA and plastid trnL intron and trnL-F intergenic spacers. Annals of Botany 98: $141-155$.

Daehler C. C. (2003) Performance comparisons of co-occurring native and alien plants: Implications for conservation and restoration. Annual Review of Ecology Evolution and Systematics 34: 183-211.

Davidson A. M., Jennions M. \& Nicotra A. B. (2011) Do invasive species show higher phenotypic plasticity than native species and, if so, is it adaptive? A meta-analysis. Ecology Letters 14: 419-431.

Funk J. L. (2008) Difference in plasticity between invasive and native plants from a low resource environment. Journal of Ecology 96: 1162-1173.

Gianoli E. \& Gonzalez-Teuber M. (2005) Environmental heterogeneity and population differentiation in plasticity to drought in Convolvulus chilensis (Convolvulaceae). Evolutionary Ecology 19: 603-613. 
Godoy O., Valladares F. \& Castro-Díez P. (2011). Multispecies comparison reveals that invasive and native plants differ in their traits but not in their plasticity. Functional Ecology 25: 1248-1259.

Griffith T. M. \& Sultan S. E. (2005) Shade tolerance plasticity in response to neutral vs green shade cues in Polygonum species of contrasting ecological breadth. New Phytologist 166: $141-148$.

Håkansson S. (2003) Weeds and Weed Management on Arable Land: an Ecological Approach. CABI Publishing.

Holm L., Doll J., Holm E., Pancho J. \& Herberger J. (1997) World Weeds: Natural Histories and Distribution. John Wiley \& Sons, Inc., New York.

Hultén E., \& Fries M. (1986) Atlas of North European vascular plants: north of the Tropic of Cancer I-III. Koeltz Scientific Books, Königstein.

Hyldegaard B. \& Brix H. (2012) Intraspecies differences in phenotypic plasticity: Invasive versus non-invasive populations of Ceratophyllum demersum. Aquatic Botany 97: 49-56.

Jasieński M. and Bazzaz F. A. (1999) The fallacy of ratios and the testability of models in biology. Oikos 84: 321-326.

Jia X., Pan X.-Y., Sosa A., Li B. \& Chen J.-K. (2010) Differentiation in growth and biomass allocation among three native Alternanthera philoxeroides varieties from Argentina. Plant Species Biology 25: 85-92.

Jonsell B., ed. (2001) Flora Nordica 2. Stockholm.

Kadereit J. W. (1988) A revision of Papaver L. section Rhoeadium Spach. Notes from the Royal Botanic Garden Edinburgh 45: 225-286.

Karlsson L. M. \& Milberg P. (2003) Dormancy and germination of fresh seeds of four Papaver taxa. Aspects of Applied Biology 69: 293-298. 
393 Karlsson L. M. \& Milberg P. (2007) A comparative study of germination ecology of four 394 Papaver taxa. Annals of Botany 99: 935-946.

395 Lamb E. G., Cahill J. F. \& Dale M. R. T. (2006) A nonlinear regression approach to test for 396 size-dependence of competitive ability. Ecology 87: 1452-1457.

397 McNaughton I. H. \& Harper J. L. (1964) Papaver L. Journal of Ecology 52: 767-793.

398 Milberg P., Lamont B. B. \& Pérez-Fernández M. A. (1999) Survival and growth of native and 399 exotic composites in response to a nutrient gradient. Plant Ecology 145: 125-132.

400 Miner B.G., Sultan S.E., Morgan S.G., Padilla D.K. \& Relyea R.A. (2005) Ecological $401 \quad$ consequences of phenotypic plasticity. Trends in Ecology and Evolution 20: 685-692.

402 Muth N. Z. \& Pigliucci M. (2006) Traits of invasives reconsidered: phenotypic comparisons 403 of introduced invasive and introduced noninvasive plant species within two closely $404 \quad$ related clades. American Journal of Botany 93: 188-196.

405 Nilsson S. G. \& Nilsson I. N. (2004) [Biodiversity at Linnaeus’s birthplace in Stenbrohult, 406 southern Sweden 4. The vascular plant flora and its changes.] Svensk Botanisk Tidskrift 407 98: 65-160. (in Swedish with English summary)

408 Peacor S. D., Allesina S., Riolo R. L. \& Pascual M. (2006) Phenotypic plasticity opposes $409 \quad$ species invasions by altering fitness surface. PLoS Biology 4 (11), e372 doi:10.1371/journal.pbio.0040372

411 Poorter H. \& Lambers H. (1986) Growth and competitive ability of a highly plastic and 412 marginally plastic genotype of Plantago major in a fluctuating environment. Physiologia

414 Richards C. L., Bossdorf O., Muth N. Z., Gurevitch J. \& Pigliucci M. (2006) Jack of all 415 trades, master of some? On the role of phenotypic plasticity in plant invasions. Ecology $416 \quad$ Letters 9: 981-993. 
417 Semchenko M., Lepik M., Götzenberger L. \& Zobel K. (2012) Positive effect of shade on

418 plant growth: amelioration of stress or active regulation of growth rate? Journal of $419 \quad$ Ecology 100: 459-466.

420 Weigelt A. \& Jolliffe P. (2003) Indices of plant competition. Journal of Ecology 91: 707-720. 
$422 \quad$ Figure legends

423 
$424 \quad$ Figure 1
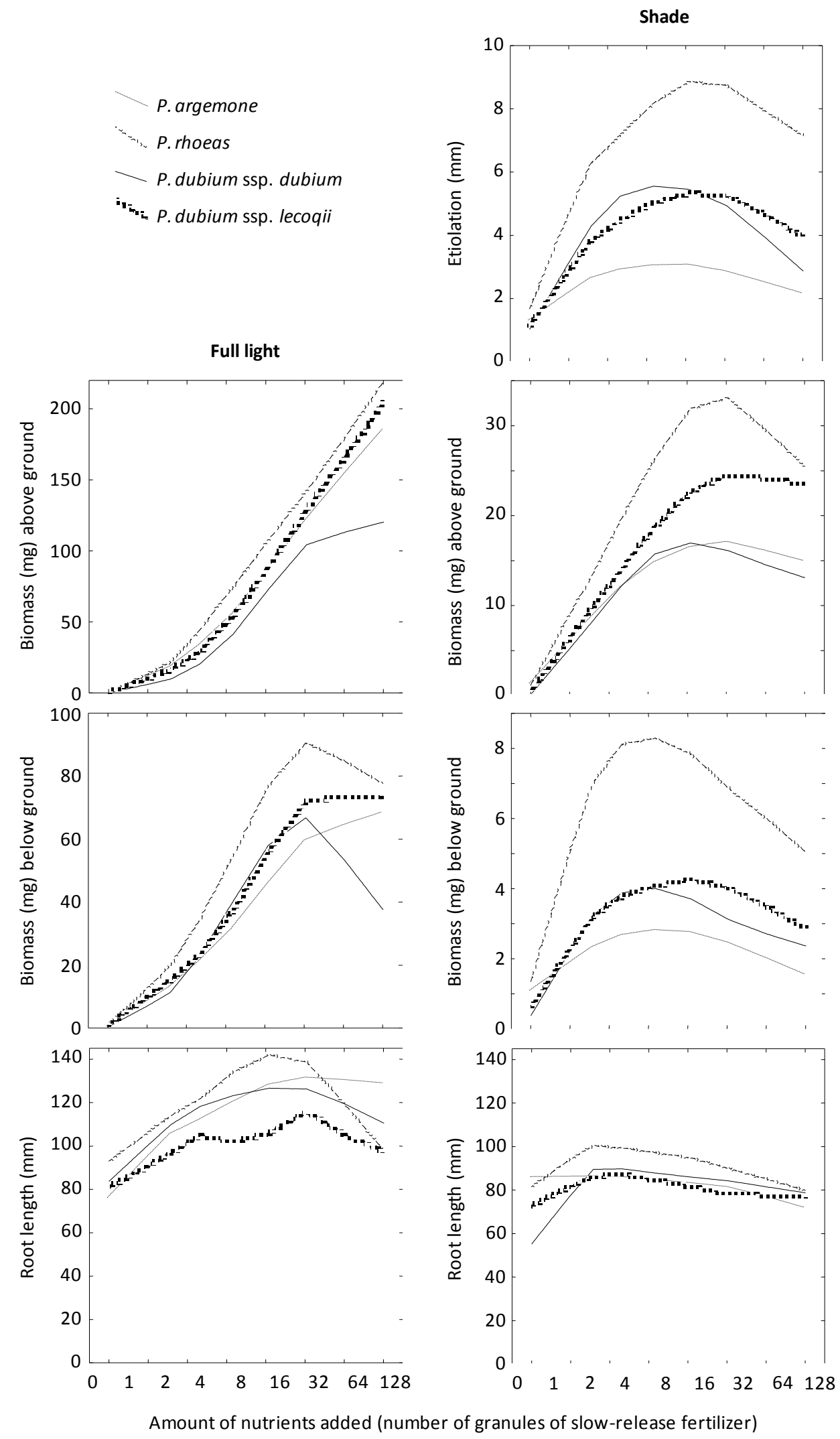
429 Fig 1. Attributes of four Papaver taxa, two populations of each, after six weeks of growth in 430 seven fertilization levels and two light conditions: full light and shaded (20\% of the intensity

431 in full light). Curves are fitted lowess (locally weighted scatterplot smoothing) to data on

432 individual plants. Root length was measured as the stretched longest root plus hypocotyl, and 433 etiolation as the length of epicotyl (present only in shadow).

434 
Figure 2
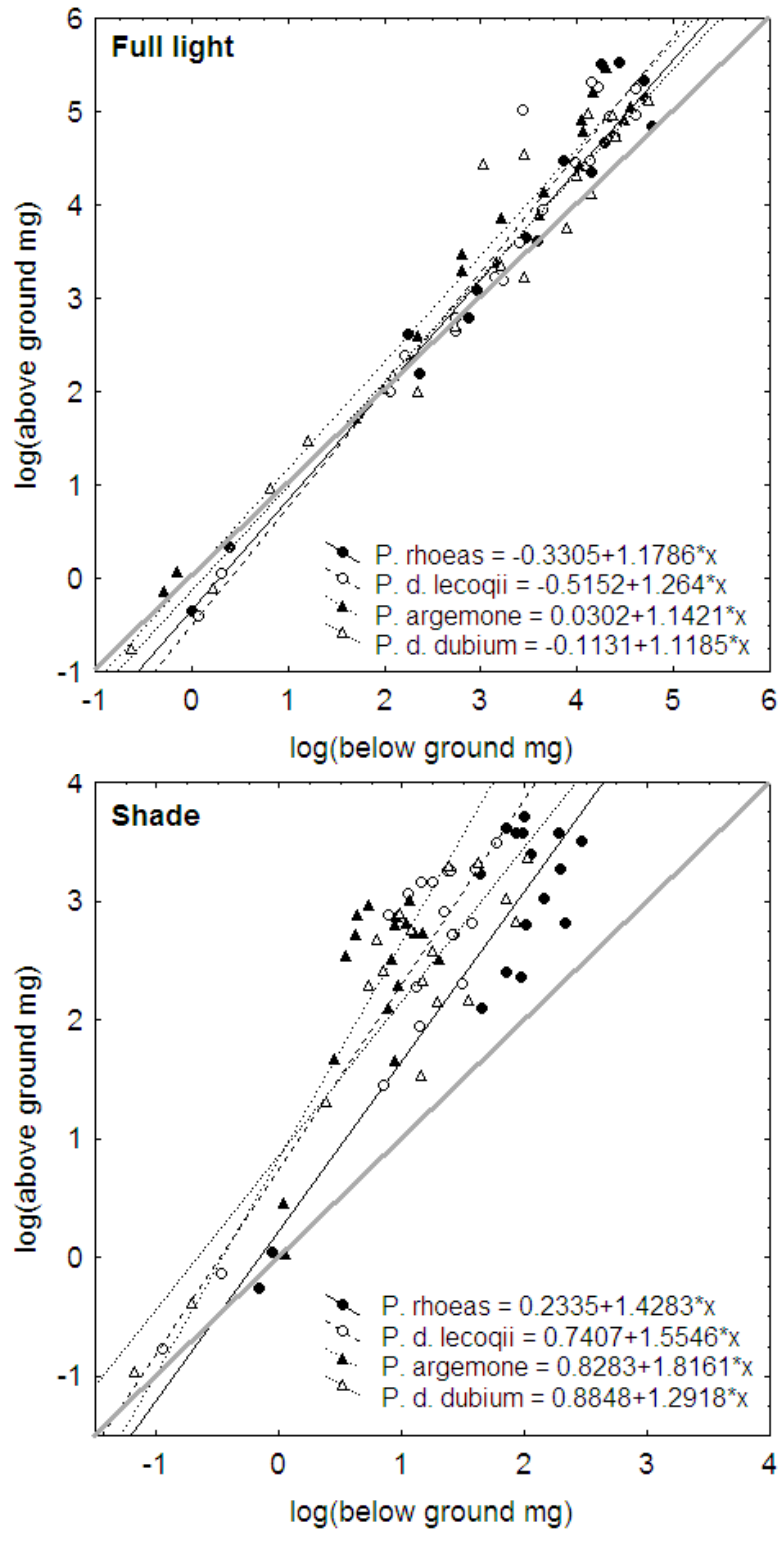

439 Fig. 2 Root/shoot ratio of four Papaver taxa, two populations of each, after six weeks of

440 growth in two light conditions; full light and shade (20\% of the intensity in full light). Grey 441 line indicate root/shoot ratio 1. 
Figure 3
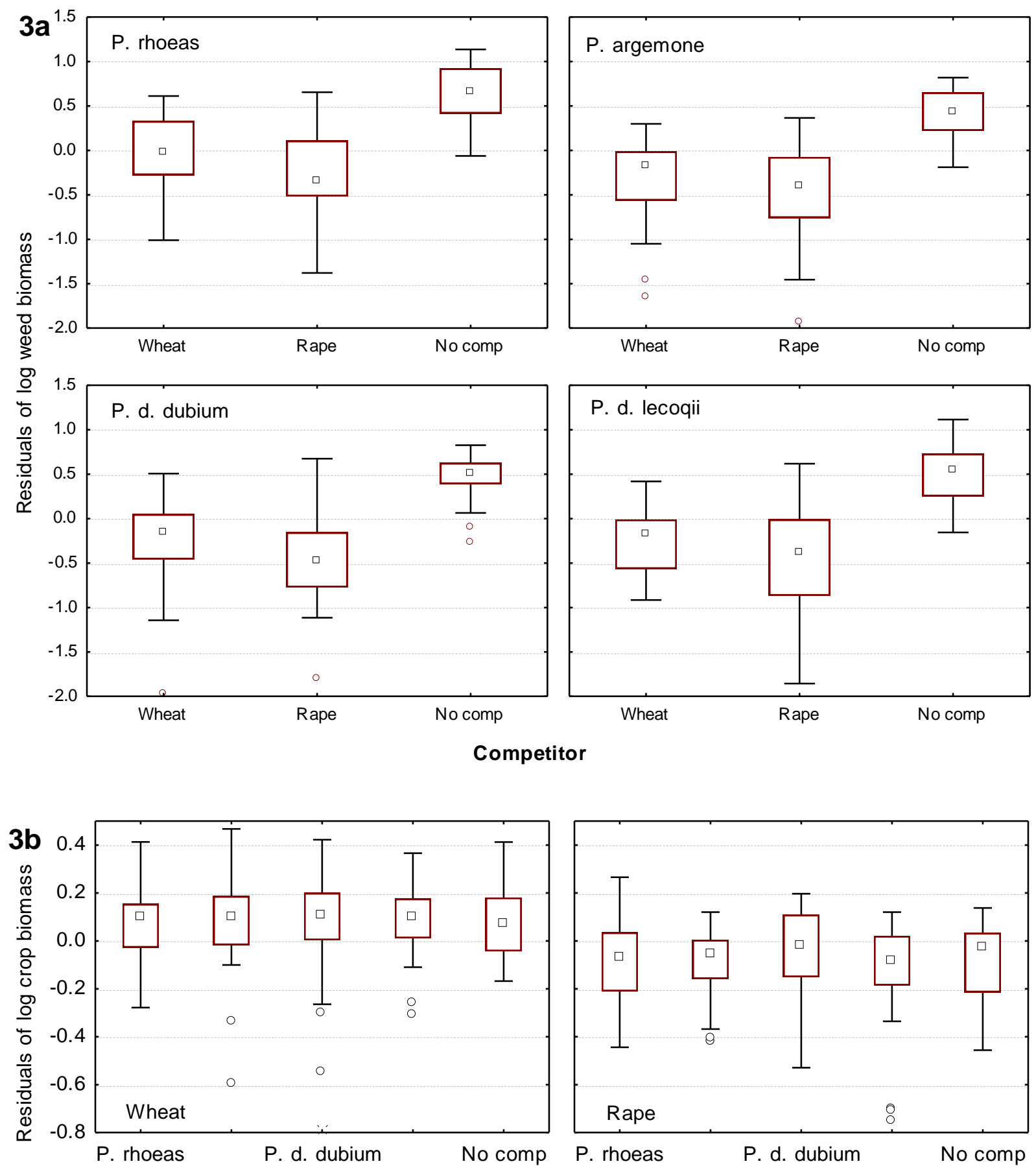
$P$. argemone

P. d. lecoqii

P. argemone

P. d. lecoqii 
447 Fig. 3 Boxplots of residuals from taxon-wise ANOVAs of four Papaver taxa, two

448 populations of each, grown using nutrient level and as the only explanatory variable. 3a)

449 Weed species (Papaver), and 3b) Crop species.

450 


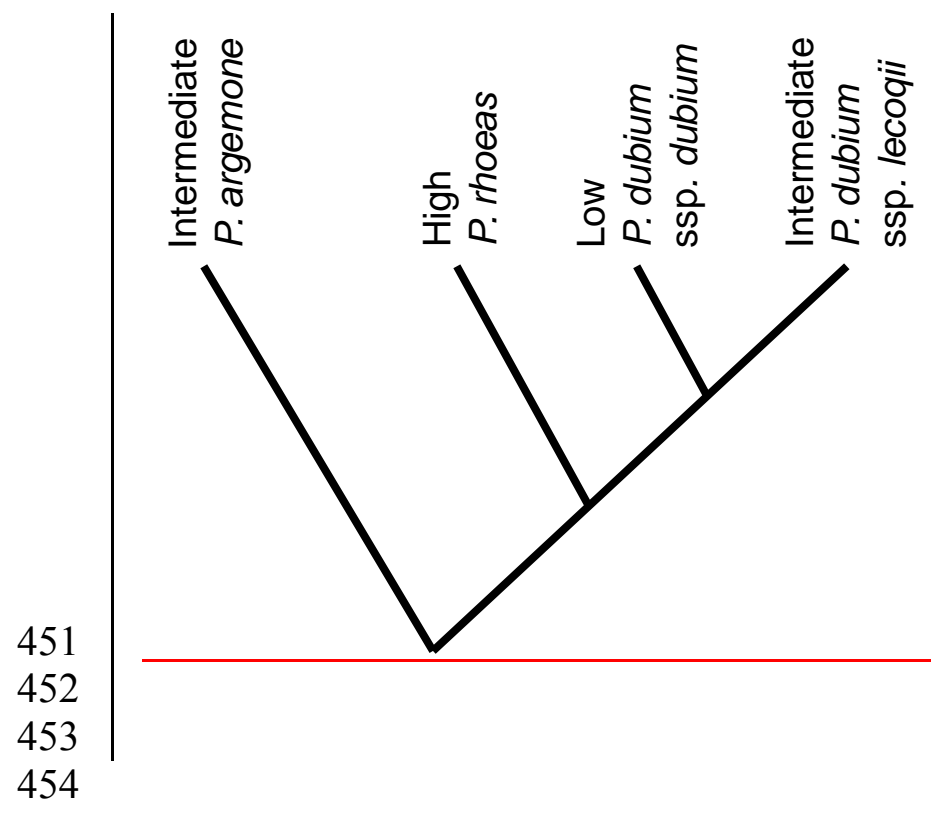

455 Fig. 4 Principal phylogeny (from Carolan et al. 2006) of four Papaver taxa (two populations

456 of each) studied regarding growth response to nutrients and light; extent of plasticity in ability 457 to exploit recourses during early growth found to be low, intermediate or high. 
Table 1. Places and dates of collections, and seed characteristics, for Papaver taxa used to study biomass allocation and competitive response.

\begin{tabular}{|c|c|c|c|c|}
\hline$\underline{\text { Taxon }}$ & $\underline{\text { Place of collection }}$ & $\begin{array}{l}\text { Date of } \\
\text { collection }\end{array}$ & $\begin{array}{l}\underline{\text { Seed }} \\
\underline{\text { mass }} \\
\underline{(\mathrm{mg})}\end{array}$ & $\begin{array}{l}\text { Embryo } \\
\underline{\text { length }} \\
\underline{(\mathrm{mm}(\mathrm{SD} ;} \\
\underline{\mathrm{N}=20))}\end{array}$ \\
\hline P. argemone & Omberg $\left(58^{\circ} 17^{\prime} \mathrm{N} 14^{\circ} 40^{\prime} \mathrm{E}\right)$ & $\underline{15 \text { July } 2002}$ & $\underline{28}$ & $\underline{0.40(0.046)}$ \\
\hline$\underline{P . \text { argemone }}$ & $\underline{\text { Ledberg }\left(58^{\circ} 26^{\prime} \mathrm{N} 15^{\circ} 28^{\prime} \mathrm{E}\right)}$ & 15 July 2002 & $\underline{27}$ & $\underline{0.43(0.059)}$ \\
\hline$\underline{\text { P. dubium ssp. dubium }}$ & $\underline{\text { Knivinge }\left(58^{\circ} 29^{\prime} \mathrm{N} 15^{\circ} 29^{\prime} \mathrm{E}\right)}$ & $\underline{17 \text { July } 2002}$ & $\underline{21}$ & $\underline{0.38(0.032)}$ \\
\hline P. dubium ssp. dubium & $\underline{\text { Tallbacken }\left(58^{\circ} 25^{\prime} \mathrm{N} 15^{\circ} 29^{\prime} \mathrm{E}\right)}$ & $\underline{17 \text { July } 2002}$ & $\underline{25}$ & $\underline{0.41(0.034)}$ \\
\hline P. dubium ssp. lecoqii & $\underline{\text { Glänås }\left(58^{\circ} 20^{\prime} \mathrm{N} 14^{\circ} 50^{\circ} \mathrm{E}\right)}$ & $\underline{17 \text { July } 2002}$ & $\underline{21}$ & $\underline{0.29(0.052)}$ \\
\hline$\underline{P . d u b i u m \mathrm{ssp} . \text { lecoqii }}$ & $\underline{\text { Vadstena }\left(58^{\circ} 27^{\prime} \mathrm{N} 14^{\circ} 53^{\prime} \mathrm{E}\right)}$ & $\underline{25 \text { Aug. } 2002}$ & $\underline{24}$ & $\underline{0.28(0.034)}$ \\
\hline$\underline{\text { P. rhoeas }}$ & $\underline{\text { Vadstena }\left(58^{\circ} 27^{\prime} \mathrm{N} 14^{\circ} 52^{\prime} \mathrm{E}\right)}$ & $\underline{19 \text { July } 2002}$ & $\underline{26}$ & $\underline{0.51(0.071)}$ \\
\hline P. rhoeas & $\underline{\text { Strå }\left(58^{\circ} 24^{\prime} \mathrm{N} 14^{\circ} 54^{\prime} \mathrm{E}\right)}$ & 19 July 2002 & $\underline{23}$ & $\underline{0.40(0.059)}$ \\
\hline
\end{tabular}


464 $\underline{\text { different light and nutrient conditions. }}$

$\underline{\mathrm{DF}} \quad \underline{\mathrm{MS}} \quad \underline{\mathrm{F}} \quad \underline{\mathrm{P}}$

$\underline{\text { Average total biomass }}$

A Taxon

$\underline{3}$

$\underline{0.469}$

$\underline{27.5}$

$\leq 0.000001$

$\underline{\text { B Light condition }}$

$\underline{1}$

$\underline{11.8}$

$\underline{690}$

$\leq 0.000001$

$\underline{\text { C Nutrient }}$

$\underline{8}$

$\underline{4.85}$

$\underline{284}$

$\leq 0.000001$

$\underline{A * B}$

$\underline{3}$

$\underline{0.0250}$

$\underline{1.46}$

$\underline{0.231}$

$\underline{\mathrm{A} * \mathrm{C}}$

$\underline{24}$

$\underline{0.0131}$

$\underline{0.769}$

$\underline{0.761}$

$\underline{B} \cdot \mathrm{C}$

$\underline{8}$

$\underline{0.458}$

$\underline{26.9}$

$\leq 0.000001$

$\underline{\mathrm{A} * \mathrm{~B} * \mathrm{C}}$

$\underline{24}$

$\underline{0.0139}$

$\underline{0.816}$

$\underline{0.705}$

Error

$\underline{72}$

$\underline{0.0170}$

\section{$\underline{\text { Root/shoot ratio }}$}

$\begin{array}{lllll}\underline{\mathrm{A} \text { Taxon }} & \underline{3} & \underline{0.178} & \underline{8.80} & \underline{0.000048} \\ \underline{\mathrm{B} \text { Light condition }} & \underline{1} & \underline{7.22} & \underline{356} & \underline{<0.000001} \\ \underline{\mathrm{C} \text { Nutrient }} & \underline{8} & \underline{1.11} & \underline{54.9} & \underline{<0.000001} \\ \underline{\mathrm{A} * \mathrm{~B}} & \underline{3} & \underline{0.0478} & \underline{2.36} & \underline{0.0787} \\ \underline{\mathrm{A} * \mathrm{C}} & \underline{24} & \underline{0.0188} & \underline{0.929} & \underline{0.565} \\ \underline{\mathrm{B} * \mathrm{C}} & \underline{8} & \underline{0.101} & \underline{4.98} & \underline{0.000062} \\ \underline{\mathrm{A} * \mathrm{~B} * \mathrm{C}} & \underline{24} & \underline{0.0262} & \underline{1.29} & \underline{0.200} \\ \underline{\text { Error }} & \underline{72} & \underline{0.0203} & & \end{array}$

